\title{
Using the internal inguinal ring as a landmark for the safe placement of secondary trocars at laparoscopy
}

\section{Jayasundara DMCS ${ }^{a}$, Senanayake $\mathrm{HM}^{\mathrm{b}}$, Samarasinghe SHMEC}

\author{
Abstract \\ Key words \\ Inferior epigastric vessels; laparoscopic vascular injuries; trans -illumination; internal inguina \\ ring \\ Aim
}

Avoidance of injury to the epigastric vessels is an important safety consideration in siting secondary ports at laparoscopy. We evaluated trans-illumination, direct visualization of vessels and using the internal inguinal ring, which has a constant relationship with the inferior epigastric vessels as an anatomical landmark to locate these vessels.

\section{Methods}

Ninety consecutive women undergoing laparoscopy were recruited for the study. The Ability to trans-illuminate the superficial and inferior epigastric vessels, to visualize inferior epigastric vessels and to locate the round ligament entering the internal inguinal ring were documented. The body mass index (BMI) was noted. The association of the body mass index (BMI)with these variables was calculated by simple regression analysis.

\section{Results.}

Ability to visualize the internal inguinal ring was significantly higher than that of locating the superficial or inferior epigastric vessels by trans -illumination or by directvisualization. $p<$ 0.001 .

Ability to visualize and to trans -lluminatethe inferior epigastric vessels decreased with increasing BMI $(p<0.05)$. There was no significant relationship between body mass index and the ability to visualize the round ligament entering the deep inguinal ring. $(p=0.64)$

\section{Conclusion}

Locating the deep inguinal ring and using it as an anatomical landmark and placing the lateral trocars lateral to a saggital line originating from the internal ring is a reliable and useful method in preventing unintended injury to anterior abdominal wall vessels during secondary trocar placement

\section{INTRODUCTION}

With evolution of technology and instruments, laparoscopy has achieved a preeminent role in gynaecologic surgery.

${ }^{a}$ Senior Lecturer in Obstetrics and Gynaecology, Dept of Obstetrics and Gynaecology, Faculty of Medicine, University of Peradeniya, Sri Lanka.

${ }^{b}$ Chair Professor of Obstetrics and Gynaecology, Dept. of Obstetrics and Gynaecology, Faculty of Medicine, University of Colombo, Sri Lanka.

${ }^{c}$ Registrar in Radiology, Teaching Hospital, Peradeniya, Sri Lanka.

Correspondence: Dr. D.M.C.S. Jayasundara, MBBS MD MRCOG

Email :-chandanasj@yahoo.com

Competing interests: The authors report no conflict of interest 0 to account for one of the two fatalities reported in their series ${ }^{4}$. In addition, significant morbidity and litigation results from damage to abdominal wall vessels as well ${ }^{5}$. In a study done on entry-related laparoscopic injuries in Finland, it was foundthat $10 \%$ of all entry related injuries occurreddue to small vessel injuries with one case needing laparotomy to achieve hemostasis ${ }^{6}$. Injury to epigastric vessels could also create a nuisance, with blood trickling down to the operative field ${ }^{7}$.

In most patients it is possible to avoid these injuries by identifying the vessels by direct laparoscopic visualization and by trans-illumination ${ }^{8}$.Standard teaching dictates that the inferior epigastric vessels should be identified either by transillumination or direct visualization?. Trans -illuminationcan often identify the superficial vessels but except in the extremely thin individuals, transillumination of inferior epigastric vessels are difficult ${ }^{8}$. Direct visualization of the inferior epigastric vessels by laparoscope is also not possible in all patients, especially in the obese ${ }^{7}$

It has been suggested that other landmarks may have to be considered prior to insertion of secondary trocars for the above reasons ${ }^{8}$.Inferior epigastric vessels arise from the external iliac vessels just before they enter the femoral canal ${ }^{10}$. They then run on the medial margin of the internal inguinal ring to run along the under surface of the lateral third of the rectus abdominis muscle ${ }^{10}$. Its course can be surface marked on the anterior abdominal wall in thin individuals from a point midway between the pubic symphysis and anterior superior iliac spine $^{10}$. As it runs superiorly its distance from the midline reduces. The distance from the midline to the inferior epigastric vessels at the level of the pubis is $7.5 \mathrm{~cm}$ while at the level of the umbilicus it is $4.6 \mathrm{~cm}^{1}$. Since its relationship to the medial margin of the internal ring is consistent, entry of the round ligament provides a convenient pointer to the internal inguinal ring. At laparoscopy, displacement of the uterus in the opposite direction using 
the uterine manipulator will make this identification easier.

Therefore, if the lateral trocars are placed lateral to a vertical line originating and extending cephalad from the internal inguinal ring, injury to the inferior epigastric vessels could be avoided.

The objective of this study was to determine the effectiveness of trans -illumination, direct visualization and using the internal inguinal ring as an anatomical landmark to locate the epigastric vessels to safely place secondary ports. We also compared the value of each of these methods with variation of body mass index (BMI).

\section{METHOD}

A prospective descriptive study was conducted at the Professorial Gynaecology unit of the Teaching Hospital, Peradeniya, Sri Lanka. Ethical clearance was obtained from the Ethics Review Committee of the Faculty of Medicine of the University of Peradeniya. Informed written consent was obtained from all the participants in the study. Ninety consecutive women undergoing laparoscopy for gynaecologic indications were included in the study. The body weight in kilograms and the height in centimeters, was recorded prior to surgery. The Veress needle was inserted trans-umbilically to create the pneumo-peritoneum in all patients and the abdominal cavity insufflated with carbondioxide gasto a filling pressure of $20 \mathrm{mmHg}$. A $10 \mathrm{~mm}$ trocar was inserted via the umbilicus and the laparoscope introducedthrough this trocar.

The ability to identify superficial and inferior epigastric vessels by transillumination and the ability to directly visualize the inferior epigastric vessels by laparoscopy were recorded. Trans ilumination was done by switching off the theatre lights and visualizing the vessels through the skin while holding the laparoscope intra abdominally with the laparoscope light on, And direct visualization was done using the laparoscope to visualize the inferior epigastric vessels running underneath the peritoneum in the anterior abdominal wall. The ability to locate the round ligament entering the deep ring and visualization of the origin of the inferior epigastric vessels intraabdominally by laparoscopic inspection was also recorded.
To differentiate between superficial and deep vessels the assistant applied firm perpendicular pressure over the vessel located via trans- illumination. Laparoscopically it was determined whether this coincided with the direction of the inferior epigastric vessels ${ }^{8}$. If the inferior epigastricvessels were visualized directly it was also inspected for 5 to $8 \mathrm{~cm}$ above the pubic symphysis since this area has been shown to be ideal for placement of the trocar ${ }^{11}$.This was done on both sides of the abdomen. The rest of the surgical procedure was done according to the surgery being carried out.

Proportions of cases with positive resultswere compared usingthe chisquare test. A $p$ value of $<0.05$ was considered to be significant. The relationship of the effectiveness of trans -illumination, direct visualization and the use of the internal inguinal ring as an anatomical landmark to locate the epigastric vessels with changes in BMI was evaluated using simpleregression analysis.The statistical package Minitab (Version 15) was used.

\section{RESULTS}

A total of 90 women with a mean age of 31.8 years (range21-44years, SD; 4.95) were enrolled.The mean BMI was $23.9 \mathrm{~kg} /$ $\mathrm{m}^{2}$ (range $15.6-43 \mathrm{~kg} / \mathrm{m}^{2}, \mathrm{SD} ; 4.93$ ) with 55 having a BMI $<25 \mathrm{~kg} / \mathrm{m}^{2}$ and 35 having a BMI $>25 \mathrm{~kg} / \mathrm{m}^{2}$

Internal inguinal ring was successfully visualized in $84(94 \%)$ patients, whereas the ability to trans-illuminate superficial epigastric vessels was successful in $50 \%$ of the cases and the ability to transilluminate inferior epigastric vessels was successful only in $30 \%$ of cases. Inferior epigastric vessels were directly visualized in $56 \%$ of cases of which $38 \%$ of cases it was also visualized $5 \mathrm{~cm}-8 \mathrm{~cm}$ above the pubic symphysis which is the area commonly

\begin{tabular}{|l|c|c|}
\hline & Right & Left \\
\hline Visualization of round ligament entering internal inguinal ring & 84 & 76 \\
\hline Transillumination of superficial epigastric vessels & 38 & 42 \\
\hline Transillumination of inferior epigastric vessels & 25 & 25 \\
\hline Direct visualization of inferior epigastric vessels & 50 & 41 \\
\hline Direct visualization of inferior epigastric 5-8cm above pubic symphysis & 33 & 34 \\
\hline
\end{tabular}

used to insert the lateral trocars.(Table 1)

Ability to visualize the internal inguinal ring was significantly higher than the ability to visualize superficial or inferior epigastric vessels either by trans-illumination or directly from the laparoscope $(p<0.001)$. (Table 2$)$. Ability to trans - illuminate the superficial epigastric and inferior epigastric as well as ability to visualize the inferior epigastric vessels directly from the laparoscope decreased with increasing BMI $(\mathrm{p}<$ $0.05)$ However there was no significant relationship between the BMI and the ability to visualize the round ligament entering the deep inguinal ring. $(\mathrm{p}=0.64)$. (Table 3).

\section{DISCUSSION}

Visualization of the internal inguinal ring was easier than direct visualization or trans- illumination of the superficial and inferior epigastric vessels. The fact that visualization of internal inguinal ring was unaffected by BMI increases its value as a landmark in introducing the lateral ports.

Superficial epigastric vessels were more amenable to trans- illumination than inferior epigastric vessels and there was a strong inverse relationship between the BMI and the ability to trans-illuminate the superficial and inferior epigastric vessels. This same relationship was observed when the inferior epigastric vessels were visualized directly using the laparoscope. These findings have been reported in previous studies as well ${ }^{8}$.

The above findings indicate that traditional methods of avoiding lateral abdominal wall vessel injuries during placement of lateral trocars at laparoscopy like transillumination and direct visualization are helpful when the patient is of normal BMI. These methods become less reliable when the patient becomes overweight

\section{Table 1 Success of Methods used for safe placement of the secondport $(n=90)$}


Table 2 Comparison of Success of Methods used for safe placement of the second port $(n=90)$

\begin{tabular}{|l|l|l|l|}
\hline Method & Comparison & $\begin{array}{l}\text { Percentage } \\
\text { Visualized }\end{array}$ & p value \\
\hline $\begin{array}{l}\text { Visualization of at least one } \\
\text { round ligament entering } \\
\text { internal inguinal ring }\end{array}$ & $\begin{array}{l}\text { Trans illumination of inferior } \\
\text { epigastric vessel }\end{array}$ & $94 \%$ vs 30\% & $<0.001$ \\
\hline $\begin{array}{l}\text { Transillumination of inferior } \\
\text { epigastric vessels }\end{array}$ & $\begin{array}{l}\text { Direct visualization of inferior } \\
\text { epigastric vessel }\end{array}$ & $30 \%$ vs $56 \%$ & $<0.001$ \\
\hline $\begin{array}{l}\text { Direct visualization of inferior } \\
\text { epigastric vessels }\end{array}$ & $\begin{array}{l}\text { Trans-illumination of inferior } \\
\text { epigastric vessel }\end{array}$ & $55 \%$ vs 30\% & $<0.001$ \\
\hline
\end{tabular}

Table 3 Association of the body mass index with the success of the method used for safe placement of the second port $(n=90)$

\begin{tabular}{|l|l|c|c|}
\hline \multicolumn{2}{|l|}{ Method } & $\begin{array}{c}\text { Maximum } \\
\text { likelihood ratio } \\
\text { Chi Square }\end{array}$ & p Value \\
\hline $\begin{array}{l}\text { Visualization of at least one round ligament entering internal } \\
\text { inguinal ring }\end{array}$ & 0.212 & 0.64 \\
\hline & Superficial Epigastric Vessels & 5.119 & 0.02 \\
\cline { 2 - 4 } & Inferior Epigastric Vessels & 15.273 & 0.001 \\
\hline & $\begin{array}{l}\text { Inferior Epigastric Vessels at } \\
\text { their Origin }\end{array}$ & 5.231 & 0.02 \\
\cline { 2 - 4 } & $\begin{array}{l}\text { Inferior Epigastric Vessels } \\
\text { at 5cm-8cm above pubic } \\
\text { symphysis }\end{array}$ & 4.166 & 0.04 \\
\hline
\end{tabular}

or obese. This disadvantage was not seen when using internal inguinal ring as an anatomical landmark to locate the origin of the inferior epigastric vessels and placing the lateral trocars lateral to a saggital line extending cephalad from the internal ring. The use of anatomical landmarks as a guide to placing lateral trocars has been described in other studies as well ${ }^{8.11}$.However none of these studies have suggested the use of round ligament entering the internal ring as an anatomical landmark for this purpose. Using midline trocars are also helpful in avoiding lateral abdominal wall vessel injuries but not all gynaecologists are comfortable doing surgeries with midline secondary trocars.

Our study population consisted only of women in the District of Kandy, Sri lanka and we were not able to assess the effect of difference in skin color on

\section{REFERENCES}

1. Saber AA, Meslemani AM, Davis R, PimentalR.Safety zones for anterior abdominal wall entry during laparoscopy: a CT scan mapping of epigastricvessels. Annals of Surgery 2004feb;239(2):182-5.

2. Hashizume M, Sugimachi K. Needle and trocar injury during laparoscopic surgery in Japan. Surgical endoscopy. 1997 Dec 1;11(12):1198-201.

3. Saidi MH, Vancaillie TG, White AJ, Sadler RK, Akright BD, Farhart SA. Complications of major operative laparoscopy; a review of 452 cases. Reprod Med 1996;41:471-6.

4. Jansen FW, Kapiteyn K, TrimbosKempers T, Hermans J, TrimbosJB. Complications of laparoscopy: a prospective multicentreobserva- tional study. Br J ObstetGynaecol1997; 104: 595-600.

5. Hurd WW, Pearl ML, DeLancey JO, Laparoscopic injury of abdominal wall blood vessels: a report of three cases. ObstetGynecol1993; 82(4 Pt 2 Suppl.):673-676.

6. Härkki-Sirén P. The incidence of entryrelated laparoscopic injuries in Finland. Gynaecological Endoscopy. 1999 Dec 1;8(6):335-8.

7. Munro MG. Laparoscopic access: complications, technologies, and techniques. Current Opinion in Obstetrics and Gynecology. 2002 Aug 1;14(4):365-74.

trans - illumination of anterior abdominal wall vessels. This could be verified only by conducting studies in women with different skin colours.

In conclusion, identifying the internal inguinal ring is easier than identifying abdominal wall vessels. Placing the secondary trocars lateral to a saggital line originating from the medial border of the internal inguinal ring and extending cephalad is a good method to safely insert the secondary trocars at laparoscopy. This method is not affected by the BMI of the woman.

\section{ACKNOWLEDGEMENTS}

Dr SampathTennakoon, Senior lecturer in Community Medicine, Faculty of Medicine, University of Peradeniya assisted with the statistical analysis
8. Hurd WW, Amesse LS, Gruber JS, HorowitzGM, Cha GM, Hurteau JA. Visualization of the epigastric vessels and bladder before laparoscopic trocar placement.Fertility and Sterility2003July;80(1):209-212

9. Royal Collage of Obstetricians and Gynaecologists: preventing entry related gynaecological laparoscopic injuries, Green-top guideline No 49, May 2008.

10. Sinnatamby CS. Last's anatomy: regional and applied. Elsevier Health Sciences; 2011 Apr 19: 215-221.

11. Hurd WW, Bude RO, Delancy JOL, Newman JS. Location of abdominal wall blood vessels in relationship to abdominal landmarks apparent at laparoscopy. Am J ObstetGynecol 1994;171:162-6. 